\title{
Infection Control of Spatial Disseminated Multi- Antibiotics Resistant And Phylo-Diverse Staphylococcus Aureus Pathotypes
}

PAUL AKINDUTI ( $\sim$ paul.akinduti@covenantuniversity.edu.ng)

Covenant University https://orcid.org/0000-0003-0697-8176

Joshua Osiyemi

University of llorin

Temitope Banjo

Crawford University

Oluwaseun Ejilude

Olabisi Onabanjo University

Maged Ashker

Mansoura University Faculty of Veterinary Medicine

Adeyemi Gideon Adewale

Covenant University

Yemisi Dorcas Obafemi

Covenant University

Patrick Isibor

Covenant University

Abiola Oladotun

Federal University of Agriculture

\section{Research}

Keywords: Antibiotics resistance, mecA, Spa types, Staphylococus aureus, Virulence genes

Posted Date: May 19th, 2020

DOl: https://doi.org/10.21203/rs.3.rs-28235/v1

License: (c) (i) This work is licensed under a Creative Commons Attribution 4.0 International License.

Read Full License 


\section{RESEARCH}

\section{Infection control of spatial disseminated multi-antibiotics resistant and phylo-diverse Staphylococcus aureus pathotypes}

Akinduti P.A $\mathrm{A}^{1^{*}}$, Osiyemi J.O², Banjo T.T ${ }^{3}$, Ejilude $\mathrm{O}^{4}$, Maged El-Ashker ${ }^{5}$, Adeyemi G. $\mathrm{A}^{6}$, Obafemi Y.D ${ }^{1}$, Isibor P. $\mathrm{O}^{1}$, Oladotun A.T

Correspondence:

Paul.akinduti@covenantuniversity.edu.ng ${ }^{1}$ Microbiology Unit, Department of Biological Sciences, Covenant university, Ota, Nigeria. Full list of author information is available at the end of the article.

\section{INTRODUCTION}

\begin{abstract}
Focal dissemination of multi-antibiotic resistant (MAR) Staphylococci pathotypes regulated by agr functionalities was investigated and evaluated for infection control. Non-repetitive Staphylococcus aureus strains from soft and skin infections disseminated in several communities were recovered and biotyped, assayed for biofilm and profiled for antibiotic resistance. Strains were further genotyped for spatypes, virulence and resistant genes; and mapped for geospatial distribution. Clonal diversity and functional accessory gene regulators (agr) were also evaluated. Staphylococcal infection was not significant with age group ( $p>0.05)$, but high rate of MSSA (53.0\%) and MRSA (1.5\%) was observed. Median resistance rates were significantly differ $(p=0.001)$ but highest $75^{\text {th }}$ percentile and media resistance rates were observed in wound infection. Resistance rate of $78.8 \%$ at $\mathrm{MIC}_{50} 32 \mu \mathrm{g} / \mathrm{ml}$ and $\mathrm{MIC}_{90} 128 \mu \mathrm{g} / \mathrm{ml}$ to amoxicillin-clavulanate, and more than $40 \%$ resistance to ceftazidime, ciprofloxacin, gentamycin, ofloxacin, sulfamethoxazole and tetracycline with $\mathrm{MIC}_{90}$ and $\mathrm{MIC}_{50}$ at $32 \mu \mathrm{g} / \mathrm{ml}$ were observed. More than 0.83 multi-antibiotic resistance index (MARI) were observed among the strains that clustered into separate phylo-group expressing high betalactamase and strong biofilm production. Heterogeneous spatypes $t 442$ (wound and pus), t657 (wound), t091 (ear) and t657 (ear and wound) revealed high phylodiversity. Only $4.6 \% \mathrm{pvl}+\mathrm{MSSA}-\mathrm{CC} 1 \mathrm{agrl}, \mathrm{pvl}+\mathrm{MSSA}-\mathrm{CC} 5$ (13.6\%) and pvl+ MRSA-CC7 agr II (4.6\%), expressed enterotoxin; sea, sec, sed, sej, Leukocidins ( LukF-PV, lukD, lukE), proteases (aur, $s / p A s s p B, s s p E$ ) and resistance genes (fosB, msr (A), bla mph(C),aphA3, sat, fosB, sdrM, Q7A4X2). Phylogenetic related spa types of livestock origin, specifically bovine milk clustered with detected strains that were prevalent in urban communities with focal dissemination to other nearest suburbs. Clonal dissemination resistant pvl+MAR MSSA-CC1 and MRSACC5 encoding agr were predominant in several peri-urban communities. This require adequate geno-surveillance, population-target antimicrobial stewardship, extensive community health care intervention policy and well-structured infection control programs to prevent further focal dissemination.
\end{abstract}

Keywords: Antibiotics resistance, mecA, Spa types, Staphylococus aureus, Virulence genes

Staphylococcal infection remains a major health challenge in several countries, with a huge resultant adverse effect ranging from life-threatening diseases such as pneumonia, bacteremia to high mortality cases [1]. Several clonal complexes have been reported from different regions of the globe [2], while various spa types kept 
evolving with diverse genomic recombination, phylogenetic clones, and repeated nucleotide mutations, giving rise to fatal virulent strains [3]. In addition, there is a capability of numerous clonal strains of Staphylococcus aureus to adapt by its specificity for colonization through production of poly- $\mathrm{N}$-acetylglucosamine to produce biofilm needed to evade immune response and antibiotic activity [4].

Severity of staphylococci infection correlates with virulence expression which is regulated through the functionality of accessory gene regulators (agr), which encodes a two-component signal transduction system that could down-regulate surface proteins metabolism and up-regulate secreted proteins during in vitro growth [5], favoring the transcription of several secreted virulence factors (particularly enterotoxins, hemolysins, and TSST-1) [6]. Functional agr groups were reported to enhance persistent staphylococci bacteraemia and soft tissue tropism with low antibiotic susceptibility to penicillin, cephalosporin and vancomycin $[7,8]$. Similar clonal spread of MRSA (methicillin-resistant Staphylococcus aureus) and MSSA (methicillin-susceptible Staphylococcus aureus) is becoming pandemic in many several communities in Africa, mostly Nigeria where animal husbandry, behavioural responses and declined demographic factors enhance continuous dissemination of staphylococcal infection with high degree of antibiotic resistance [9]. The misuse and unregulated prescription of penicillin derivatives in high and uncontrollable proportion for treating several extra-intestinal infections such as abscess, ear infections, subcutaneous tissue inflammation, nasal discharges particularly in children and postsurgical wound culminated in a high rate of resistance and continuous development of methicillin-resistance strains $[10,11]$.

Heterogenous spa types identified among several MSSA and MRSA carriers and infected subjects [12] require clonal diversity and staphylococcal infection surveillance, tracking and strains genotyping [13, 14]. Moreover, a repeated evolution of various spa types has kept driving dynamics spread of staphylococcal infection that were demonstrated in various infection outbreaks, localized epidemics and community-acquired infections. Mapping the spread and dissemination of mecA gene among spa types is highly needed for reliable genomic tracking, localization and control of staphylococcal infection in several local communities with high-level dissemination and distribution of resistant spa types probably acquired from livestock [12].

In this study, we investigated the antibiotic resistance distribution and prevalence of agr groups of phylodiverse $S$. aureus strains characterized by various spa repeats and assessed the potential association between different agr group functionalities, severity and staphylococci infection controls.

\section{METHODS}

Isolates collection: Non-repetitive clinical samples totaling 256 including purulent pus $(n=58)$, aspirates $(n=34)$, wounds $(n=55)$ and otitis media $(n=36)$, eye infection $(n=14)$, throat $(n=35)$ and endocervical $(n=24)$, collected between June 2017 and August 2018 from outpatients attending three major health facilities which serves as referral clinics in southwest Nigeria. Ethical permissions for the study were obtained and data on their gender, age, disease conditions and subjects' location of residence were not fully retrieved. Each sample were cultured for Staphylococci strains and phenotypically characterized on Baird-Parker agar and Mannitol salt agars, Gram stained for cellular morphology, tested for catalase and coagulase production as previously discussed [15]

Phenotypical beta-lactamase detection and antibiogram: Beta-lactamase production was assayed with modified starch-acidometric method [16] and Minimum inhibitory concentrations (MICs) for each antibiotic class against the strain was determined using micro-broth dilution assay [17] with 12 panel antibiotics consisting of tetracycline, ceftazidime, ciprofloxacin, gentamycin, ampicillin, amoxycillin-clavulanic acid, cefuroxime, ofloxacin, sulfamethoxazole, erythromycin, penicillin, vancomycin and Linezolid. Phenotypic resistance was interpreted 
according to CLSI guidelines [18]. Phenotypic screening for methicillin resistance was further determined by assessment of Staphylococci growth on Mannitol salt agar and Mannitol salt agar supplemented with $4 \mu \mathrm{g} / \mathrm{ml}$ Oxacillin as previously described [19].

Biofilm detection and mecA and pvl genotyping: Phenotypic assessment of biofilm production was done in micro-broth bioassay [20]. Extracted DNA template was genotyped for mecA gene using mec5 (AAAATCGATGGTAAAGGTTGGC) and mec6 (AGTTCTGCAGTACCGGATTTGC) primers (following previous described protocol and $p v l$ gene with primers pvl-F (AATGAAATGTTTTTAGGCTCAAGACA) and pvl-R (TGGATAACACTGGCATTTTGTGA) [21]. Amplicon products were electrophoresed on 1.5\% agarose gel. Multiantibiotic resistance index (MARI), degree of biofilm production, beta-lactamase production and mecA relatedness among the strains were evaluated with dendrogram analysis constructed with DendroUPGMA algorithm.

Genotyping and clonal diversity of spa types: Extracted genomic DNA obtained from overnight culture, was typed for S. aureus protein A (spa gene). PCR assay was performed in constituted reaction mixture of 2x MyTaq

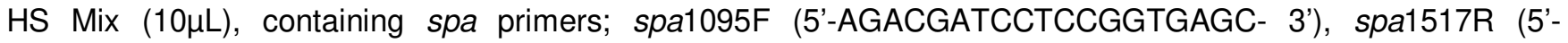
GCTTTTGCAATGTCATTTACTG-3') of $5 \mu \mathrm{L}$ each and $1 \mu \mathrm{L}$ template DNA through 30 cycles of denaturation at $94^{\circ} \mathrm{C}$ for 30 seconds, annealing at $60^{\circ} \mathrm{C}$ for 30 seconds and elongation at $72^{\circ} \mathrm{C}$ for 30 seconds, with final extension at $72^{\circ} \mathrm{C}$ for 5 minutes [22, 23]. DNA of $S$. aureus DSM 1104L strain served as a positive and distilled water as negative control. Quality of amplicon products was examined on electrophoresed agarose gel and positive strains were purified with GFX PCR DNA and Gel Band Purification Kit (GE Healthcare). Purified PCR products were sequenced with forward primer spa1095F using BigDye 3.1 terminator sequencing and analyzed on ABI Genetic Analyzer 3500Dx (Applied Biosystems, CA, USA). Categorisation of spa types was carried out with Based Upon Repeat Pattern (BURP) algorithm of the Ridom Staph Type software version 1.4 (RidomGmbH, Sedanstr, Germany) to cluster all spa types in the database according to spa clonal complexes [24]. Clonal diversity of Nigerian spa types with meta-spa sequences were analysed with MEGA software (version 6.0).

Virulence and resistance genotyping: $S$. aureus strains were further genotyped with StaphyType DNA microarray (Alere Technologies $\mathrm{GmbH}$, Jena, Germany). Approximately 170 distinct genes and their allelic variants were targeted for PCR amplification and hybridization on Microtiter strip-mounted DNA microarrays following manufacturer's instruction and the image of the array was recorded and analysed using a designated reader and software (Arraymate, Iconoclust, Alere Technologies) [25].

Geospatial analysis: Geographical coordinates of individual subjects with staphylococci infection were identified and recorded with differential global positioning system (GIS) and interpolated for analysis in ArcGIS programme with respect to land division according to boundary marks in southwest Nigeria [26].

Data analysis: To identify variables and risk factors that could influence staphylococci infection rate among dependent variables (age, gender and clinical samples), univariate logistic regression analyses was performed to calculate the odds ratio and corresponding $95 \%$ confidence intervals, taking $p$ value $<0.05$ statistically significant. Median and $75^{\text {th }}$ percentile resistance were evaluated with Boxplot analysis using SPSS 20. Significance of resistance level of staphylococci strains was determined with chi-square and staphylococci infectivity was calculated with multiple comparison using Kruskal-wallis test, taking $p<0.05$.

\section{RESULTS}

Risk factor for Staphylococcal infection and phenotypic resistance pattern: Staphylococcal infection was not significant with age $(p>0.05, O R[C l]=0.021[0.545-1.914])$. Though, staphylococcal infection was not 
significant among gender, but higher rate of MSSA (53.0\%) and MRSA (1.5\%) infection were recorded among female subjects. MSSA (37.9\%) and MRSA (1.5\%) infection rates were significant in wound infection as other clinical conditions presented by the subjects $(p<0.05)$ while MSSA $(42.2 \%)$ were observed in other conditions (eye, throat and endocervical infection) as shown in Table 1. Figure 1 is a Box plot of overall antibiotic resistance rates of staphylococci strains in different clinical condition to all the 12 panel antibiotics excluding susceptible strains isolated from eye, throat and endocervical samples. Estimated median resistance of staphylococci strains in all the clinical disease conditions were significantly differ $(p=0.001)$, no significant difference was observed in overall resistance but strains from aspirates and otitis had close median resistance rates $(p=0.056)$. Highest percentile $\left(75^{\text {th }}\right)$ and median resistance were observed in wound strains than others. Overall resistance rate of $78.8 \%$ to $A M C$ at $\mathrm{MIC}_{90}(128 \mu \mathrm{g} / \mathrm{ml})$ was recorded for strains obtained from aspirates, while strains recovered from pus, ear and wound infections showed more than $30 \%$ resistance at $\mathrm{MIC}_{50}(8-16 \mu \mathrm{g} / \mathrm{ml})$. Only $59.3 \%$ of $S$. aureus strains recovered from pus and aspirate were resistant to $\mathrm{CRO}$ at $\mathrm{MIC}_{90}(64 \mu \mathrm{g} / \mathrm{ml})$ and $\mathrm{MIC}_{50}(8 \mu \mathrm{g} / \mathrm{ml})$, respectively. More than $40 \%$ of $S$. aureus strains obtained from aspirate had high resistance to TET (MIC 90 and $\mathrm{MIC}_{50}$ at $\left.64 \mu \mathrm{g} / \mathrm{ml}\right)$, while strains recovered from pus were resistant to $\mathrm{CN}\left(\mathrm{MIC}_{90}\right.$ and $\mathrm{MIC}_{50}$ at $128 \mu \mathrm{g} / \mathrm{ml}$ and $16 \mu \mathrm{g} / / \mathrm{ml}$ ), respectively (Table 2 ).

Resistance relatedness of extra-intestinal $S$. aureus strains: Only four $S$. aureus strains recovered from aspirate, otitis media and wound expressed $\operatorname{mec} A$ gene (Figure 2), 17 strains clustered into group $C$ with similar MARI of more than 0.50 , characterized with biofilm and high beta-lactamase production. More than $0.83 \mathrm{MARI}$ were observed among the strains that clustered into group A with high number of strains producing betalactamase and strong biofilm, but only one strain of MARI 0.92 clustered to Group D.

Clonal diversity: Heterogeneous spa types from extra-intestinal staphylococci strains clustered meta-spa types into six separate clades, of which spa 4442 (from wound and pus), t657 (wound), t091 (otitis media) and t657 (otitis media and wound) clustered into clade F1 with other spa types from blood stream and soft tissue infection (red rectangular). High phylogenetic relatedness of spa sequences of livestock-associated $S$. aureus strains (bovine milk) clustered with with the human strains (Figure 3).

Encoded agr and focal dissemination: Clonal strains pvl+ MSSA-CC1 (4.6\%) obtained from wound samples, of spa t1839, majorly encoded exfoliative toxin (etD, etB), proteases (aur, $s / p A s s p B, s s p E, s s p P$ ) and resistant determinants; bla (beta lactamase repressor (inhibitor) and beta-lactamase regulatory protein); fosB (Metallothiol transferase); sdrM (tet efflux protein) and Q2YUB3 (Multidrug resistance transporter) (Table 3), expressed agr functionality. Obviously, 13.6\% pvl+ MSSA belonging to clonal lineage CC5 from pus, wound and abscess harboured numerous heterogeneous spa types with functional agrl encoding enterotoxin sea, sec, sed, sej, sel, ser), leukocidins (LukF-PV, lukD, lukE) and proteases (aur, $s / p A s s p B, s s p E, s s p P$ ). In addition, agrl was also recorded in $4.6 \% \mathrm{pvl}+\mathrm{MRSA}-\mathrm{CC} 7$ strains of spa t091 characterized with LukF-PV, lukD, lukE, proteases and aphA3, (3,5-aminoglycoside phosphotransferase encoding neomycin/ kanamycin resistance); sat (Streptothricineacetyltransferase); tetK (Tetracycline resistance markers); $m s r$ (A) (Macrolide efflux); and $m p h(C)$, (lysylphosphatidyl-glycerol synthetase). Most MSSA strains were observed to be prevalent at urban communities showing focal dissemination to other nearest suburbs while identified MRSA was observed to be spreading together with other MSSA strains (Figure 4).

\section{DISCUSSION}

Continuous spread of staphylococcal infection in several communities is now becoming a threat to the populace and mostly the children. Methicillin susceptible $S$. aureus infections are now commonly observed among the 
children with high risk of sores, blood stream infection, and scalded skin infection which are recorded due to low immunity, poor hygiene and possible transmission from Staphylococci-carrier mothers [27]. Occupation and routine activities of many young adults and men could be considered a pre-disposing risk factor. Data relating subject occupation with staphylococcal infection was not available but recorded MRSA and MSSA detection in wound largely suggest stemming increase and spread of community-acquired staphylococcal infections [28]. Nosocomial staphylococcal infection could not be ruled out as hospital infection control could be compromised due to low hygiene and staff carriage of multi-antibiotic resistance Staphylococci strains [29]. A significant low susceptibility was observed among the strains collection to ceftazidime, ciprofloxacin, amoxycillin-clavulanic acid and cefuroxime. Particularly strains from wound, ear, pus and aspirates showed a reflection of prolonged use and misuse of antibiotics in the treatment of staphylococcal infections. Continuous evolution and selective pressure of antibiotic resistance cannot be ruled out as a driven factor for the prevalence of resistant pathotypes across various population groups as evident with more than $40 \%$ resistance to tetracycline at $\mathrm{MIC}_{90}(64 \mu \mathrm{g} / \mathrm{ml})$ and $\mathrm{MIC}_{50}$ at $(8 \mu \mathrm{g} / \mathrm{ml})$.

The ability to treat multi-antibiotic resistant staphylococci strain characterized with biofilm is a challenging situation [30] and detection of different phylo-related strains expressing high level antibiotic resistance with potential to produce both biofilm and beta-lactamase enzymes put the populace at great risk [31]. Antibiotic resistance relatedness of several MSSA showing observable in-vitro biofilm production reflects acute systemic infection severity and pathology that could progress to high morbidity [32,33], making MSSA-biofilm producing strains in soft tissue and skin infections difficult to treat [34]. High biofilm production in deep layer secretions in cases of septic wound, tissue abscess and purulent pus exudates could reduce drug penetration, inflammatory response and impairment of cellular immune activity [35]. In addition, strains with high MARI beta-lactamase and high biofilm production are considered important pathotypes that needed to be designated for surveillance and assessment among diverse population at different localities. It is highly imperative to have periodic surveillance for these clusters with related resistance profile toward prevention of local sporadic outbreak and control of antibiotic misuse. However, unregulated prescription and abuse of antibiotics in several local communities in southwest Nigeria largely contribute to increase circulating resistant phylo-groups. Relative increase of resistant MRSA isolates to penicillin derivatives has been found to be associated with encoded mecA gene and betalactamase production which is a major factor to be considered towards achievable control of MRSA spread [36]. In addition, identification of heterogeneous spa types in extra-intestinal infections clearly showed high phylodiverse spa strains clustering into various different clades. In spite of this strain-diversity, profound relatedness with other meta-spa types suggests high level dissemination of similar clonal groups [37]. This is a clear evidence of involvement of spa types in single or multiple staphylococcal infections having high substantial impact through localization and distribution in soft tissue for adaptation, colonization and pathogenesis thereby initiating severe infection [38, 39].

Identified phylo-diverse MSSA from Nigerian communities indicates active clonal transfer from other locations [40]. Detection of heterogeneous spa sequences from various skin and soft-tissue infections (wound, abscess and pus), is an evidence of genetic recombination of spa repeats from livestock-associated staphylococci particularly from bovine milk [41]. This further establish animal to human transfer which is observed in most communities where animal husbandry is usually practice within and around the households. Consumption of unpasteurised bovine milk, poor milk wastes disposal and frequent human contact with udder during animal milking are observable, is usually predisposing risk factors to be considered as major sources and spread of diverse spa strains with high level antimicrobial resistance traits [41]. It is also important to note that reported multi-antibiotic 
resistant MRSA identities in this study could perpetuate severity with little or no therapeutic options. Scratches, pecking and bite on human skin by poultry, cattle and other livestock cannot be ruled out as major contributor to animal clonal strains found among this populace. It is imperative to investigate mechanism of animal transfer of spa types to human and high prevalence of these associated livestock spa types. It is also necessary to evaluate the emerging animal clonal spa types vis-a-vis animal husbandry and antibiotic residue in milk in order to safeguard the populace and drastically reduce dissemination and risk of contracting antibiotic resistant strains. Findings on animal related MRSA and MSSA spa types in humans, illustrates livestock involvement in continuous spread and distribution of Staphylococci pathotypes in many communities. To control the prevalent, milk hygiene and animal waste management would enhance reduction in spread and skin infectivity particularly among children.

Towards effective infection control of resistant $S$. aureus encoding functional agr having known to person wellcharacterised operons controlling and regulating exfoliative toxin and protease genes in pvl+ MSSA-CC1 strains in several wound infections [42,43], continuous and strategic interventional approaches of health care systems, door-to-door awareness program and routine MRSA and MSSA surveillance are important strategies for effective reduction of severe complications, morbidity, and occasional mortality. Predominant agr and agrll in MSSA and occurrence of agrll in pvl+ MRSA-CC7 clonally differ from agrll that were reported in Tunisia [44]. Expression of functional agrl in resistant pvl+ MSSA-CC5 and pvl+ MRSA-CC7 clones in pus, wound and abscess would further intensify invasiveness through action of enterotoxin genes (particularly sea, sec, sed, and sej), Leukocidins (LukF-PV, lukD/lukE) and proteases (aur, slpA sspB, sspE, sspP). Furthermore, bloodstream, skin and soft-tissue infections would be more severe in agr controlled staphylococcal diseases and could result in longer hospital stay, increase debilities and therapeutic failure. In rural and semi-urban settings with poor health facilities and hygiene awareness, dissemination of these resistant clonal pathotypes would exacerbate infection burden, mostly among the vulnerable elderly.

Conclusion: Control of skin and soft tissue staphylococci infections predominantly caused and spread by agr encoded $p v l+$ MSSA-CC1 and pvl+ MRSA-CC5 strains characterised with very high antibiotic resistance would require aggressive antibiotic regulation, policy and stewardship, extensive community health care intervention and well-structured strategic infection control programs. Periodic geno-surveillance and investigation of multi-antibiotic resistant zoonotic MSSA and MRSA needed to be implemented concurrently with formulated health policy to prevent imminent outbreak of these clonal pathotypes.

\section{Declarations}

Ethics approval and consent to participate: Permissions for the study were obtained from Federal Medical Centre, Abeokuta Nigeria which serves as a referral clinic for internal medicine with approval number: OG/HRR/sEED/109773 and General hospital, (GJH/DFTR/DFFT/0987) and Sacred Heart Hospital, Nigeria.

Consent for publication: Not applicable

Availability of data and materials: The datasets used and/or analysed during the current study are available from the corresponding author on reasonable request.

Competing interests: The authors declare that they have no competing interests.

Funding: Deutsche Forschungsgemeinschaft (DFG), Germany in cooperation with the World Academy of Science (TWAS), Italy provided support for genomic analysis at the Staphylococci Unit, BfR, Germany. Publication was partly supported by the management of Covenant University, Ota, Nigeria. The afore-mentioned support agents had no role in study design, data collection and analysis, interpretation of data, decision to publish, or preparation of the manuscript.

Authors' contributions: Each author has made substantial contribution as follows; PA, JO, and YD provide conception of the study; PA, JO, TT, ME, EO, GA and AT analysed and interpreted the data; PA and TT performed genomic analysis. All authors read and approved the final manuscript. 
Acknowledgements: The authors thank the management of Federal Medical Centre, Abeokuta for assisting data collection, Dr. $\mathrm{H}$. Wichmann-Schauer and Dr. S Maurischat of German Federal Institute for Risk Assessment, Unit Microbial Toxins, NRL for Coagulase Positive Staphylococci, Department Biological Safety, Berlin, Germany for their technical assistance.

\section{REFERENCES}

1. Asadollahi P, Farahani NN, Mirzaii M, Khoramrooz SS, van Belkum A, Asadollahi K, Dadashi M and Darban-Sarokhalil D. Distribution of the Most Prevalent Spa Types among Clinical Isolates of Methicillin-Resistant and -Susceptible Staphylococcus aureus around the World: A Review. Front. Microbiol. 2018, 9:163. doi: 10.3389/fmicb.2018.00163

2. Goudarzi, M., Seyedjavadi, S. S., Nasiri, M. J., Goudarzi, H., Nia, R. S., and Dabiri, H. Molecular characteristics of methicillin-resistant Staphylococcus aureus (MRSA) strains isolated from patients with bacteremia based on MLST, SCCmec, spa, and agr locus types analysis. Microb. Pathog. 2017, 104, 328-335. doi: 10.1016/j.micpath.2017.01.055

3. Fatemeh Shakeri, Abolfath Shojai, Masoud Golalipour, Somaye Rahimi Alang, Hamid Vaez, and Ezzat Allah Ghaemi. Spa diversity among MRSA and MSSA Strains of Staphylococcus aureus in North of Iran. International Journal of Microbiology, 2010, 10: 1-5 doi:10.1155/2010/351397

4. Fernández-Barat L, Ben-Aicha S, Marco F, Motos A, Vila J, Rigol M, Muñoz L, Li Bassi G, Ferrer M, Torres A. Assessment of in vivo versus in vitro bioilm formation of clinical methicillin-resistant Staphylococcus aureus isolates from endotracheal tube. Scientific Report, 2018, 8:11906-10. DOI:10.1038/s41598-018-30494-7

5. S. Bronner, H. Monteil et G. Prevost. Regulation of virulence determinants in Staphylococcus aureus : complexity and applications. Fems. Microbiol. Rev., 2004; 28, 183-200.

6. S. Ben Ayed, I. Boutiba-Ben Boubaker, S. Ennigrou and S. Ben Redjeb. Accessory Gene Regulator (Agr) T Yping Of Staphylococcus aureus Isolated From Human Infections. Archs. Inst. Pasteur Tunis, 2008, 85 ( 1 - 4 )

7. Indrawattana N, Sungkhachat O, Sookrung N, Chongsa-nguan M, Tungtrongchitr A, Voravuthikunchai SP, et al. Staphylococcus aureus Clinical Isolates: Antibiotic Susceptibility, Molecular Characteristics, and Ability to Form Biofilm. Bio Med Research International. 2013; Article ID 314654, 11 pages.

8. Kolawole DO, Adeyanju A, Schaumburg F, Akinyoola AL, Lawal OO, Amusa YB, et al. Characterization of Colonizing Staphylococcus aureus Isolated from Surgical Wards' Patients in a Nigerian University Hospital. PLoS One. 2013;(7): e68721

9. Ayeni FA, Ruppitsch W, Allerberger F. Molecular characterization of clonal lineage and staphylococcal toxin genes from $S$. aureus in Southern Nigeria. Peer J 2018, 6:e5204; DOI10.7717/peerj.52042

10. Turlej, A., Hryniewicz, W., and Empel, J. Staphylococcal cassette chromosome mec (Sccmec) classification and typing methods: an overview. Pol. J. Microbiol, 2011; 60, 95-103.

11. Bosch, T., Pluister, G. N., Van Luit, M., Landman, F., van Santen-Verheuvel, M., Schot, C., et al. Multiple-locus variable number tandem repeat analysis is superior to spa typing and sufficient to characterize MRSA for surveillance purposes. Future Microbiol. 2015; 10:1155-1162. doi: 10.2217/fmb.15.35

12. N. Mitani, A. Koizumi, R. Sano. Molecular typing on methicillin-resistant Staphylococcus aureus by PCR-RFLP and its usefulness in an epidemiological study of an outbreak. Japanese Journal of Infectious Diseases, 2005; 58 (4): 250-252.

13. L. Louie, S. O. Matsumura, E. Choi, M. Louie, and A. E. Simor, "Evaluation of three rapid methods for detection of methicillin resistance in Staphylococcus aureus," Journal of Clinical Microbiology, 2000; 38(6): 2170-2173.

14. B. Strommenger, C. Braulke, D. Heuck, C. Schmidt, B. Pasemann, U. Nu“bel, and W. Witte. Spa Typing of Staphylococcus aureus as a Frontline Tool in Epidemiological Typing Journal of Clinical Microbiology, 2008; 46 (2):574-581. doi:10.1128/JCM.01599-07

15. Marcelle Aquino Rabelo, Armando Monteiro Bezerra Neto, Eduardo Caetano Brandão Ferreira da Silva, Wagner Luis Mendes de Oliveira, Fábio Lopes de Melo, Ana Catarina S. Lopes, Nilma Cintra Leal, Maria Amélia Vieira Maciel. Phenotypic methods for determination of methicillin resistance in Staphylococcus spp. from health care workersJ Bras Patol Med Lab, 2013; 49(2): 91-96.

16. Akinduti PA, Akinbo JA, Adenuga WF, Ejilude O, Umahoin KO and Ogunbileje JO. Occurrence of Extended-Spectrum $\beta$-lactamase Producing Enterobacteriaceae (ESBLPE) among Primary School Pupil in Obafemi-Owode, Nigeria. Journal of Life Sciences, 2011; 5: 340-344.

17. Qi C., Stratton C.W., Zheng X. Phenotypic Testing of Bacterial Antimicrobial Susceptibility. In: Advanced Techniques in Diagnostic Microbiology. Springer 2006, Boston, MA

18. Clinical and Laboratory Standards Institute. Performance standards for antimicrobial susceptibility testing, sixteenth informational supplement, document M100-S20.Wayne, PA, USA: CLSI, 2018.

19. Bignardi GE, Woodford N, Chapman A, Johnson AP, Speller D. Detection of the mec-A gene and phenotypic detection of resistance in Staphylococcus aureus isolates with borderline or low-level methicillin resistance. Journal of Antimicrobial Chemotherapy. 1996; 37:5363. PubMed: 8647774. 
20. Smith K, Perez A, Ramage G, Lappin D, Gemmell CG, et al. Biofilm formation by Scottish clinical isolates of Staphylococcus aureus. J. Med. Microbiol. 2008; 57: 1018-1023.

21. Chen FJ, Siu LK, Lin JC, Wang CH, Lu PL. Molecular typing and characterization of nasal carriage and community-onset infection methicillin-susceptible Staphylococcus aureus isolates in two Taiwan medical centers. BMC Infect Dis. 2012 Dec 10;12:343.

22. Fatemeh S, Abolfath S, Masoud G, Somaye RA, Hamid V and Ezzat AG. Spa diversity among MRSA and MSSA Strains of Staphylococcus aureus in North of Iran. International Journal of Microbiology, 2010; 10: 1-5. doi:10.1155/2010/351397

23. Shopsin, B., Gomez, M., Montgomery, S. O., Smith, D. H., Waddington, M., Dodge, D. E., Bost, D. A., Riehmann, M., Naidich, S. and Kreiswirth, B. N. Evaluation of protein A gene polymorphic region DNA sequencing for typing of Staphylococcus aureus strains. J. Clin. Microbiol. 1999; 37(11): 3556-3563.

24. Mellmann A, Weniger T, Berssenbrugge C, Rothganger J, Sammeth M, et al. Based Upon Repeat Pattern (BURP): an algorithm to characterize the long-term evolution of Staphylococcus aureus populations based on spa polymorphisms. BMC Microbiol $2007 ; 7: 98$.

25. Monecke S, Jatzwauk L, Weber S, Slickers P, Ehricht R. DNA microarray-based genotyping of methicillin-resistant Staphylococcus aureus strains from Eastern Saxony. Clinical microbiology and infection: the official publication of the European Society of Clinical Microbiology and Infectious Diseases. 2008; 14(6):534-45.

26. A. Moodley, W. F. Oosthuysen, A. G. Dusé, E. Marais. South African MRSA Surveillance Group Molecular Characterization of Clinical Methicillin-Resistant Staphylococcus aureus Isolates in South Africa. Journal of Clinical Microbiology Nov 2010, 48 (12) 4608-4611; DOI: 10.1128/JCM.01704-10

27. Hughes C, Tunney M, Bradley MC. Infection control strategies for preventing the transmission of meticillin-resistant Staphylococcus aureus (MRSA) in nursing homes for older people. Cochrane Database Syst Rev. 2013;(11): CD006354. doi:10.1002/14651858.CD006354.pub4.

28. Wyllie D, Paul J, Crook D. Waves of trouble: MRSA strain dynamics and assessment of the impact of infection control. J Antimicrob Chemother. 2011; 66(12):2685-8.

29. Köck R, Werner P, Friedrich AW, Fegeler C, Becker K, Bindewald O, et al. Persistence of nasal colonization with human pathogenic bacteria and associated antimicrobial resistance in the German general population. New Microbes New Infect. 2016; 9:24-34. http://dx.doi.org/10.1016/j.nmni.2015.11.004

30. Bui, L. M., Turnidge, J. D. \& Kidd, S. P. The induction of Staphylococcus aureus biofilm formation or Small Colony Variants is a strainspecific response to host-generated chemical stresses. Microbes. Infect. 2015; 17:77-82.

31. Akinduti P.A, Oluwadun A, Iwalokun B, Onagbesan O.M, Ejilude O. Community-Acquire CTX-M Beta-Lactamase Enteric Isolates in Abeokuta, Nigeria British Microbiology Research Journal , 2014; 5(4): 351-358.

32. Laia Fernández-Barat, Soumaya Ben-Aicha, Francesc Marco, Anna Motos, Jordi Vila, Montserrat Rigol, Laura Muñoz, Gianluigi Li Bassi, Miquel Ferrer, Antoni Torres. Assessment of in vivo versus in vitro bioilm formation of clinical methicillin-resistant Staphylococcus aureus isolates from endotracheal tubes. Scientific Reports, 2018; 8:11906. DOI:10.1038/s41598-018-30494-7

33. Akinduti PA, Olasehinde GI, Ejilude O, Taiwo OS, Obafemi YD. Fecal carriage and Phylo-Diversity of Community-Acquired bla TEM Enteric Bacilli in Southwest Nigeria. Infection and Drug Resistance, 2018; 11: 2425-2433.

34. Hu Q, Cheng H, Yuan W, Zeng F, Shang W, Tang D, Xue W, Fu J, Zhou R, Zhu J et al. Panton-Valentine leukocidin (PVL) positive health care-associated methicillin-resistant Staphylococcus aureus isolates are associated with skin and soft tissue infections and colonized mainly by infective PVLencoding bacteriophages. J Clin Microbiol. 2015; 53(1):6772.

35. Brady, R. A., Mocca, C. P., Plaut, R. D., Takeda, K. \& Burns, D. L. Comparison of the immune response during acute and chronic Staphylococcus aureus infection. PLoS. One, 2018; 13, e0195342.

36. Andreas Petersen, Xiaoliang B, Ewan M. Harrison, Giles F. Edwards, Matthew T. G. Holden, Anders Rhod Larsen, Robert L. Skov, Sharon J. Peacock, Julian Parkhill, Gavin K. Paterson and Mark A. Holmes. Novel mutations in penicillin-binding protein genes in clinical Staphylococcus aureus isolates that are methicillin resistant on susceptibility testing, but lack the mec gene. J Antimicrob Chemother, 2014; 69: 594-597. doi:10.1093/jac/dkt418.

37. Matthew T.G. Holden, Li-Yang Hsu, Kevin Kurt, Lucy A. Weinert, Alison E. Mather, Simon R. Harris, Birgit Strommenger, Franziska Layer, Wolfgang Witte, Herminia de Lencastre, Robert Skov, Henrik Westh, Helena Žemlic`kova', Geoffrey Coombs, Angela M. Kearns, Robert L.R. Hill, Jonathan Edgeworth, Ian Gould, Vanya Gant, Jonathan Cooke, Giles F. Edwards, Paul R. McAdam, Kate E. Templeton, Angela McCann, Zhemin Zhou, Santiago Castillo-Ramı'rez, Edward J. Feil, Lyndsey O. Hudson, Mark C. Enright, Francois Balloux, David M. Aanensen, Brian G. Spratt, J. Ross Fitzgerald, Julian Parkhill, Mark Achtman, Stephen D. Bentley, and Ulrich Nu“bel. A genomic portrait of the emergence, evolution, and global spread of a methicillin-resistant Staphylococcus aureus pandemic. Genome Research, 2013; 23:653-664. 
38. Becker K, Schaumburg F, Fegeler C, Friedrich AW, Köck R; Prevalence of Multiresistant Microorganisms PMM Study. Staphylococcus aureus from the German general population is highly diverse. Int $\mathrm{J}$ Med Microbiol. 2017;307:21-7. http://dx.doi.org/10.1016/j.ijmm.2016.11.007

39. Kuhn G, Koessler T, Melles DC, Francois P, Huyghe A, Dunman P, Vos MC, Zanetti G, Schrenzel J, van Belkum A. Comparative genomics of epidemic versus sporadic Staphylococcus aureus strains does not reveal molecular markers for epidemicity. Infect Genet Evol, 2010; 10: 89-96.

40. Sangeeta Joshi, Pallab Ray, Vikas Manchanda, Jyoti Bajaj, D.S. Chitnis,Vikas Gautam, Parijath Goswami, Varsha Gupta, B.N. Harish, Anju Kagal, Arti Kapil, Ratna Rao, Camilla Rodrigues, Raman Sardana, Kh Sulochana Devi, Anita Sharma, and Veeragaghavan Balaji (2013). Methicillin resistant Staphylococcus aureus (MRSA) in India: Prevalence \& susceptibility patternIndian J Med Res. 2013; 137(2): 363-369.

41. J. A. Osiyemi, O. A. Osinupebi, P. A. Akinduti, O. Ejilude, S. O. Makanjuola, N. O. Sunmola and E. O. Osiyemi (2018). Antibiotic Resistance Profile of Methicillin-Resistant Staphylococcus aureus in Abeokuta, Nigeria. Journal of Advances in Microbiology; 9(2): 1-9, 2018; Article no.JAMB.39800 ISSN: 2456-7116

42. Alba, P., Feltrin, F., Cordaro, G., Concepcion Porrero, M., Kraushaar, B., Argudin, M. A., Cloeckaert, A. Livestock-Associated Methicillin Resistant and Methicillin Susceptible Staphylococcus aureus Sequence Type (CC)1 in European Farmed Animals: High Genetic Relatedness of Isolates from Italian Cattle Herds and Humans. PLoS One, 2015; 10(8), [e0137143]. DOI: 10.1371/journal.pone.0137143

43. Novick RP, Geisinger E. Quorum sensing in staphylococci. Annual review of genetics. 2008; 42:54164. https://doi.org/10.1146/annurev.genet.42.110807.091640 PMID: 18713030

44. Jones RN. Microbial etiologies of hospital-acquired bacterial pneumonia and ventilator-associated bacterial pneumonia. Clinical infectious diseases: an official publication of the Infectious Diseases Society of America. 2010; 51 Suppl 1:S81-7.

45. Ben Ayed S, Boutiba-Ben Boubaker I, Samir E, Ben Redjeb S.. Prevalence of agr specificity Groups among methicilin resistant Staphylococcus aureus circulating at Charles Nicolle hospital of Tunis. Pathol Biol (Paris). 2006; 54 (8-9):435-8.

Authors:

Akinduti P.A

Microbiology Unit, Department of Biological Sciences, Covenant University, Ota, Nigeria

Osiyemi J.O

Department of Microbiology, University of Ilorin, Ilorin, Nigeria

Banjo T.T

Department of Microbiology, Crawford University, Igbesa, Ogun State, Nigeria

Ejilude $\mathrm{O}$

Microbiology Laboratory, Sacred Heart Hospital, Lantoro, Abeokuta, Nigeria

Maged El-Ashker

Department of Internal Medicine and Infectious Diseases, Faculty of Veterinary Medicine, Mansoura University, Mansoura 35516, Egypt

Adeyemi G.A

Microbiology Unit, Department of Biological Sciences, Covenant University, Ota, Nigeria

Obafemi Y.D

Microbiology Unit, Department of Biological Sciences, Covenant University, Ota, Nigeria

Isibor P.O

Microbiology Unit, Department of Biological Sciences, Covenant University, Ota, Nigeria

Oladotun A.T

Department of Microbiology, Federal University Of Agriculture, Abeokuta, Nigeria 


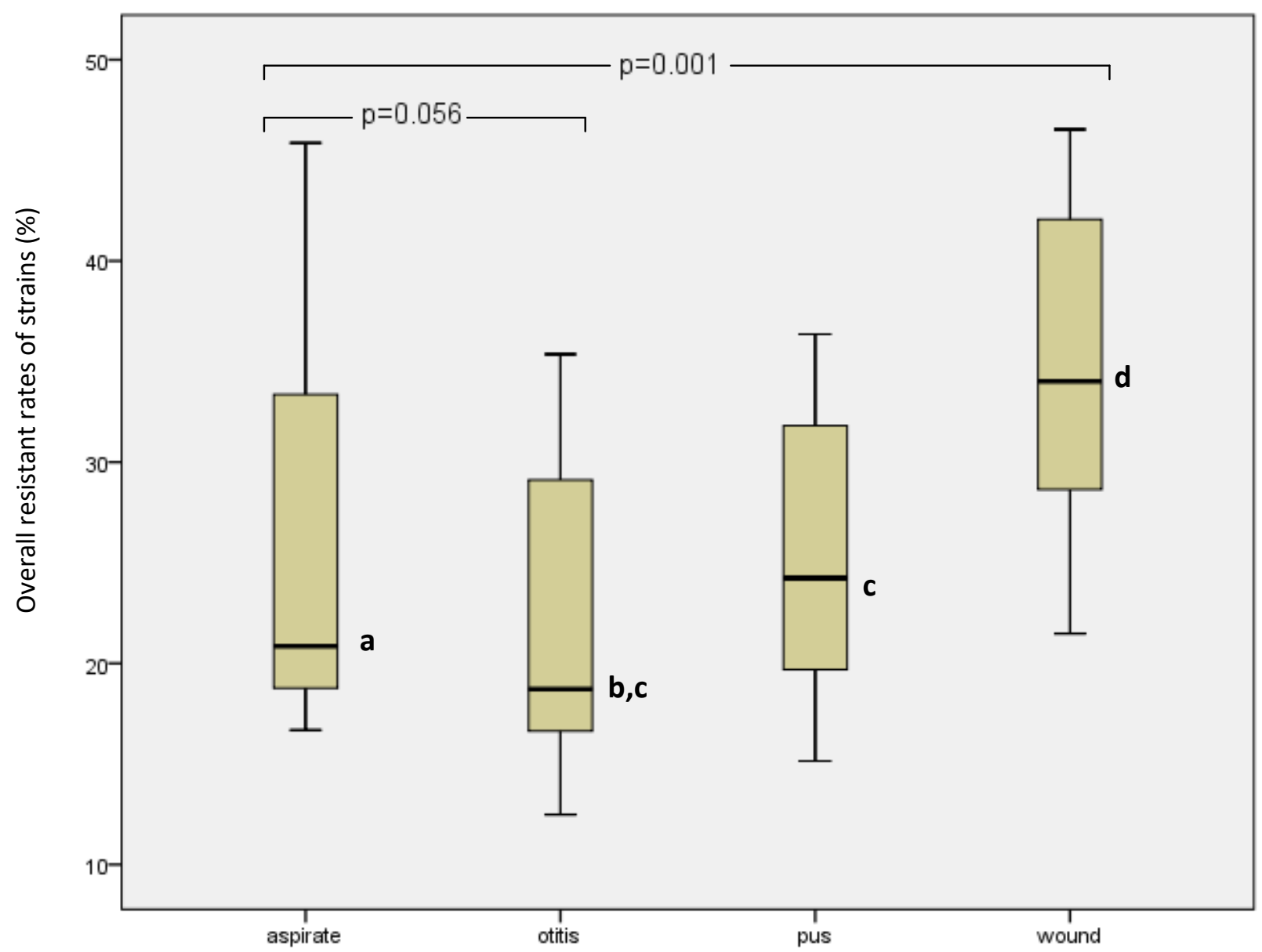

Figure 1, Box plot showing median distribution of antibiotic resistance pattern of Staphylococci strains in collected samples of aspirate $(n=13)$, otitis $(n=16)$, pus $(n=12)$ and wound $(n=25)$. Bold horizontal lines indicate median; and lower and upper whiskers indicate range of resistance rates $(p<0.05$ is significantly difference). 


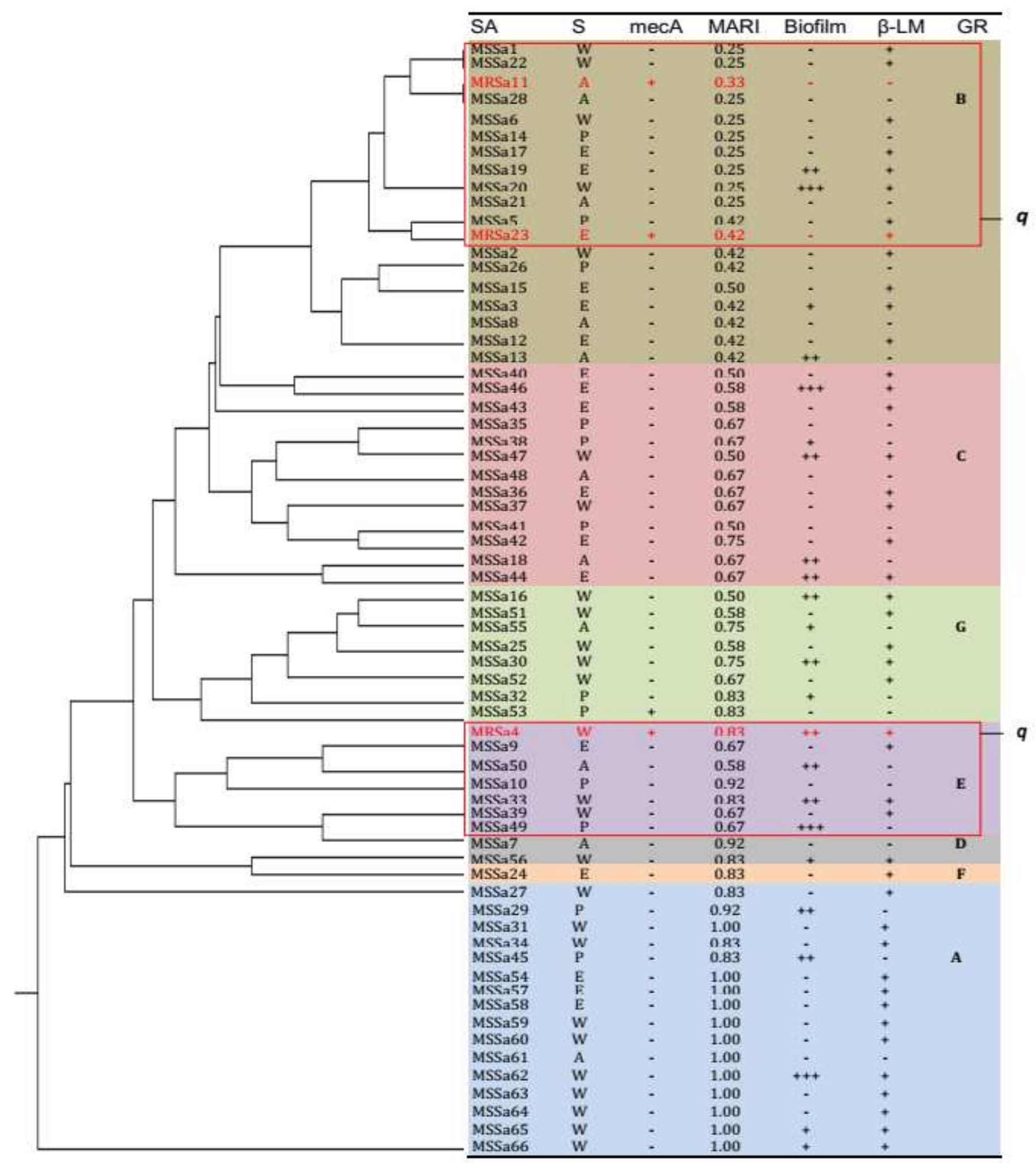

Figure 2; Phylo-antibiotic resistance relatedness with high multi-antibiotic resistance index (MARI), biofilm and beta-lactamase production and mecA genotype (note: + indicate positive and -; negative reaction, biofilm production:+, weak; ++, mild; +++ ,strong reaction; SS, Source; $\beta$-LM, beta-lactamase; W, Wound; A,Aspirate; P,Pus; E,Ear; GR, Phylo-group), q,Diverse multi-resistant strain clustering into same phylo-group. 


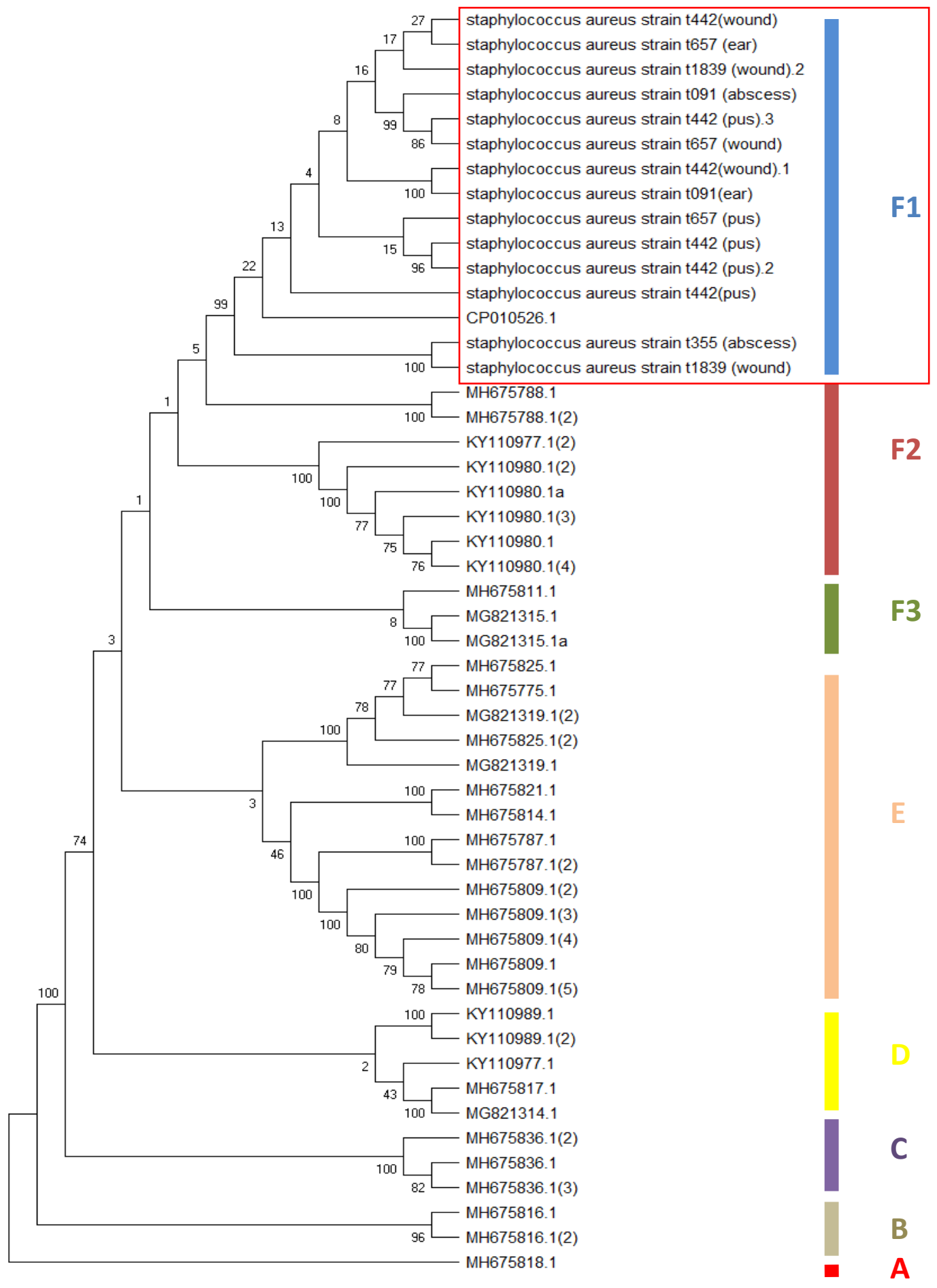

Figure 3; Neighbor-joining tree showing the phylo-diversity of Staphylococci characterized by heterogeneous spa types (t442, t657, t091, t355) and meta-spa sequences of $>95 \%$ identity with their respective accession numbers. Bootstrap values based on 1,000 replications are given at various branching points and sequence divergent was determined with the scale bar. 


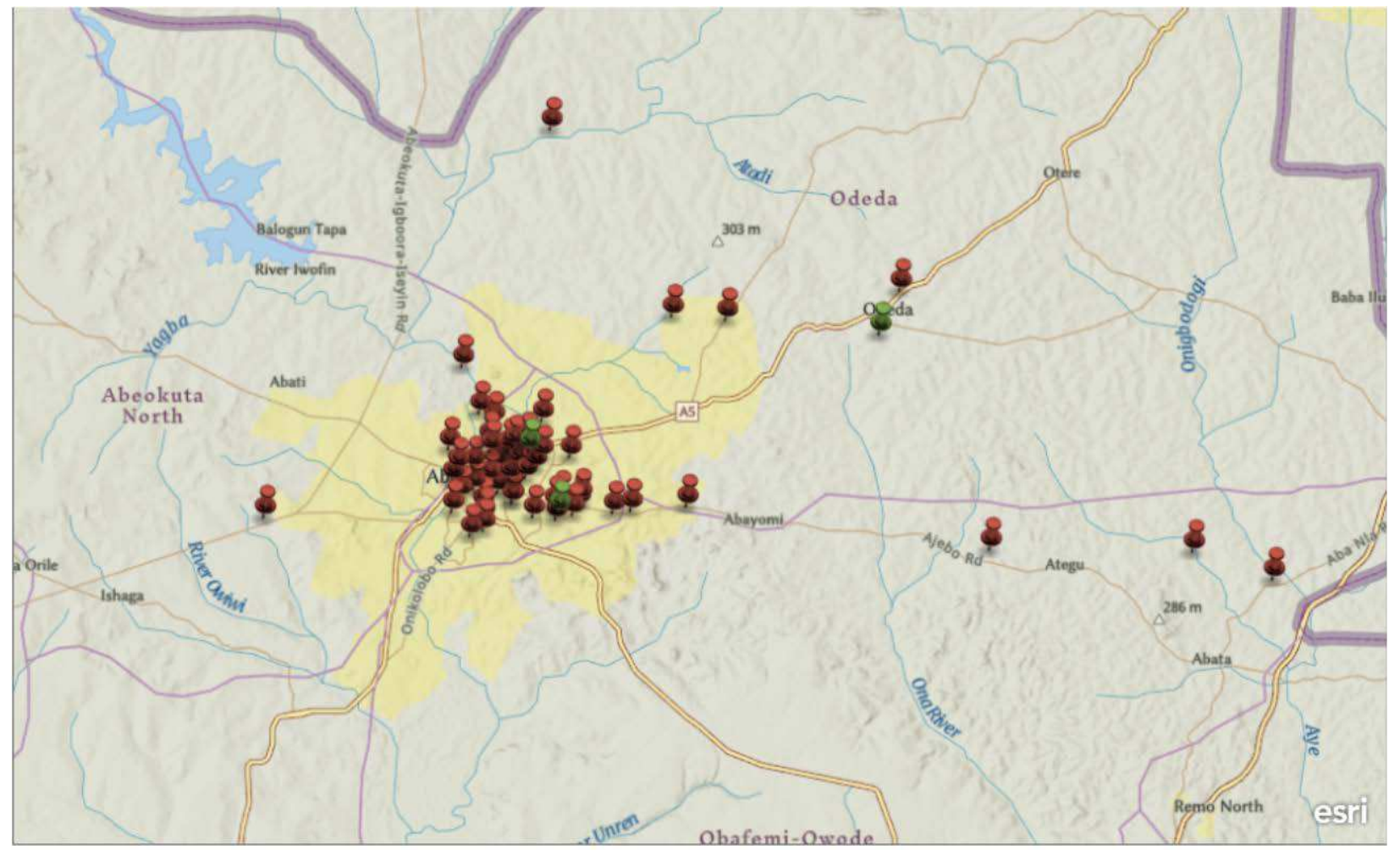

Figure 4; Geospatial mapping and focal dissemination of multi-antibiotic resistance MSSA (green pin) and MRSA (red pin) strains characterised with heterogenous spa genes in distributed in various communities divided according to boundary marks in southwest Nigeria 
Table 1: Univariate distribution and risk factors for Staphylococcal infections

\begin{tabular}{ccccc}
\hline Characteristic & $\begin{array}{c}\text { MSSA } \\
\mathbf{n}(\%)\end{array}$ & $\begin{array}{c}\text { MRSA } \\
\mathbf{n}(\%)\end{array}$ & OR(Cl) & P value \\
\hline Age (yrs) & $63(24.6)$ & $3(1.2)$ & $0.021(0.545-1.914)$ & 0.948 \\
(Range: $1-70)$ & & & & \\
Gender & $35(53.0)$ & $1(1.5)$ & $1.021(0.374-1.785)$ & 0.613 \\
Female & $31(47.0)$ & $2(3.0)$ & & \\
$\quad$ Male & & & & \\
Clinical samples & $16(24.2)$ & $1(1.5)$ & & \\
Otitis media & $25(37.9)$ & $1(1.5)$ & & \\
Wound infection & $12(18.2)$ & $0(0.0)$ & $0.434(0.569-4.183)$ & \\
Purulent pus & $13(19.7)$ & $1(1.5)$ & & \\
Aspirate effusions & $108(42.2))$ & $0(0.0)$ & & \\
${ }^{*}$ Other infections & & & \\
\hline
\end{tabular}

$(\overline{P<0.05 \text { significant, other infection include eye infection, throat and endocervical collections, }} \mathrm{n}$, number;\%, percentage rate) 
Table 2: Phenotypic resistant of $S$. aureus strains from various infection sources to antibiotics

\begin{tabular}{|c|c|c|c|c|c|c|c|c|c|c|c|}
\hline \multirow[t]{3}{*}{ Agents } & \multirow[t]{3}{*}{ Range } & \multirow[t]{3}{*}{$\begin{array}{l}\text { Break point } \\
\text { of resistanc } \\
(\mu \mathrm{g} / \mathrm{ml})\end{array}$} & \multicolumn{2}{|c|}{$\begin{array}{l}\text { Wound } \\
(n=26)\end{array}$} & \multicolumn{2}{|c|}{$\begin{array}{c}\text { Ear } \\
(n=18)\end{array}$} & \multicolumn{2}{|c|}{$\begin{array}{c}\text { Pus } \\
(n=13)\end{array}$} & \multicolumn{2}{|c|}{$\begin{array}{c}\text { Aspirate } \\
(n=9)\end{array}$} & \multirow[t]{3}{*}{$\begin{array}{l}\text { Percentage of } \\
\text { resistance } \\
(\%)\end{array}$} \\
\hline & & & \multicolumn{8}{|c|}{$\mathrm{MIC}(\mu \mathrm{g} / \mathrm{ml})$} & \\
\hline & & & $\mathrm{MIC}_{50}$ & $\mathrm{MIC}_{90}$ & $\mathrm{MIC}_{50}$ & $\mathrm{MIC}_{90}$ & $\mathrm{MIC}_{50}$ & $\mathrm{MIC}_{90}$ & $\mathrm{MIC}_{50}$ & $\mathrm{MIC}_{90}$ & \\
\hline TET & $0.25-128$ & 16 & 8 & 32 & 4 & 64 & 4 & 64 & 8 & 64 & 43.0 \\
\hline CAZ & $0.1-64$ & 4 & 4 & 64 & 4 & 32 & 16 & 64 & 2 & 32 & 36.5 \\
\hline CIP & $0.12-16$ & 4 & 4 & 16 & 1 & 64 & 2 & 64 & 1 & 32 & 38.9 \\
\hline $\mathrm{CN}$ & $0.03-2.0$ & 1 & 2 & 16 & 1 & 64 & 2 & 128 & 16 & 64 & 40.2 \\
\hline AMC & $0.25-64$ & 16 & 2 & 32 & 2 & 32 & 1 & 32 & 8 & 128 & 78.8 \\
\hline CRO & $0.1-64$ & 4 & 8 & 32 & 2 & 32 & 2 & 64 & 4 & 64 & 59.3 \\
\hline OFX & $0.12-64$ & 4 & 4 & 16 & 1 & 64 & 1 & 32 & 8 & 32 & 35.6 \\
\hline SXT & $0.5-128$ & 32 & 4 & 32 & 16 & 128 & 16 & 128 & 16 & 64 & 41.7 \\
\hline ER & $0.5-64$ & 32 & 1 & 16 & 4 & 16 & 4 & 64 & 16 & 128 & 34.0 \\
\hline FOX & $0.1-64$ & 4 & 2 & 16 & 2 & 32 & 8 & 128 & 8 & 64 & 46.5 \\
\hline LZD & $0.1-64$ & 2 & 1 & 16 & 1 & 32 & 4 & 64 & 2 & 32 & 34.2 \\
\hline
\end{tabular}

Notes: $S$. aureus; $n$, number of isolates; N,Number of samples; TET, Tetracycline; CAZ,Ceftazidime; CIP,Ciprofloxacin; CN,Gentamycin; AMC, Amoxycillin-clavulanic acid; CRO,Cefuroxime; OFX,Ofloxacin; SXT, sulfamethoxazole; ER, Erythromycin; Fox, penicillin; LZD,linezolid, MIC; Minimum inhibitory concentration. 
Table 3: Functional agr, clonal types and gene determinants in MSSA and MRSA pv/ positive strains

\begin{tabular}{|c|c|c|c|c|c|c|}
\hline $\begin{array}{l}\text { Agr } \\
\text { types }\end{array}$ & $\begin{array}{c}\text { Strains } \\
(\%)\end{array}$ & Sources & $\begin{array}{l}\text { Clonal } \\
\text { Complex }\end{array}$ & spa types & $\begin{array}{c}\text { Virulence } \\
\text { determinants }\end{array}$ & $\begin{array}{l}\text { Antibiotic resistance } \\
\text { genes }\end{array}$ \\
\hline$\overline{a g r}$ & MSSA (4.6) & wound & $\begin{array}{c}\text { CC1(ST772,S } \\
\text { T573) }\end{array}$ & t1839 & $\begin{array}{l}\text { sea, lukD, lukE, sak, } \\
\text { chp, scn, etD, etB, aur, } \\
\text { slpA sspA, sspB,sspP }\end{array}$ & $\begin{array}{l}\text { Q2YUB3, fosB, sdrM, } \\
\text { bla }\end{array}$ \\
\hline agrll & MSSA (13.6) & $\begin{array}{l}\text { Pus, wounds, } \\
\text { abscess }\end{array}$ & $\begin{array}{l}\text { CC5(ST5, } \\
\text { ST73, ST492, } \\
\text { ST1447) }\end{array}$ & $\begin{array}{l}\text { t002, t010, t053, t067, } \\
\text { t088, t179, t214, t242, } \\
\text { t442, t509, t688, t1062, } \\
\text { t1265, t6709 }\end{array}$ & $\begin{array}{c}\text { Sea, sec, sed, sej, sel, } \\
\text { ser, LukF-PV, lukD, } \\
\text { lukE, scn, aur, splA } \\
\text { sspA, sspB,sspP }\end{array}$ & $\begin{array}{l}\text { fosB, } \operatorname{msr}(A), \text { bla } \\
m p h(C), \text { aphA3, } \\
\text { sat,fosB, sdrM, Q7A4X2 }\end{array}$ \\
\hline agrll & MRSA (4.6) & wound & CC7(ST789) & t091 & $\begin{array}{l}\text { lukD, lukE, sak, scn, } \\
\text { aur, splA, slpE, } \\
\text { sspA, sspB,sspP }\end{array}$ & $\begin{array}{l}\text { bla, fosB, aacA-aphD, } \\
\text { aphA3,sat,tetK, sdrM, } \\
\text { ccrC, aacA- } \\
\text { aphD, aphA3, }\end{array}$ \\
\hline
\end{tabular}

Note: enterotoxin genes (sea, sec, sed, sej, sel, ser ); Leukocidins (LukF-PV, lukD, lukE); exfoliative toxin (etD, etB); Proteases(aur, slpA), bla (beta lactamase repressor (inhibitor) and beta-lactamase regulatory protein); fosB (Metallothiol transferase); aacA-aphD (Bifunctional enzyme Aac/Aph; gentamicin, tobramycin resistance); aphA3, (3,5-aminoglycoside phosphotransferase, neo-/ kanamycin resistance); sat (Streptothricine-acetyltransferase); tetK (Tetracycline resistance markers); sdrM (Multidrug efflux protein, tetEfflux); $m s r(A)$ (Macrolide efflux); $m p h(C)$ (Probable lysylphosphatidyl-glycerol synthetase); Q7A4X2 (Putative protein); Q2YUB3 (Multidrug resistance transporter) 
Figures

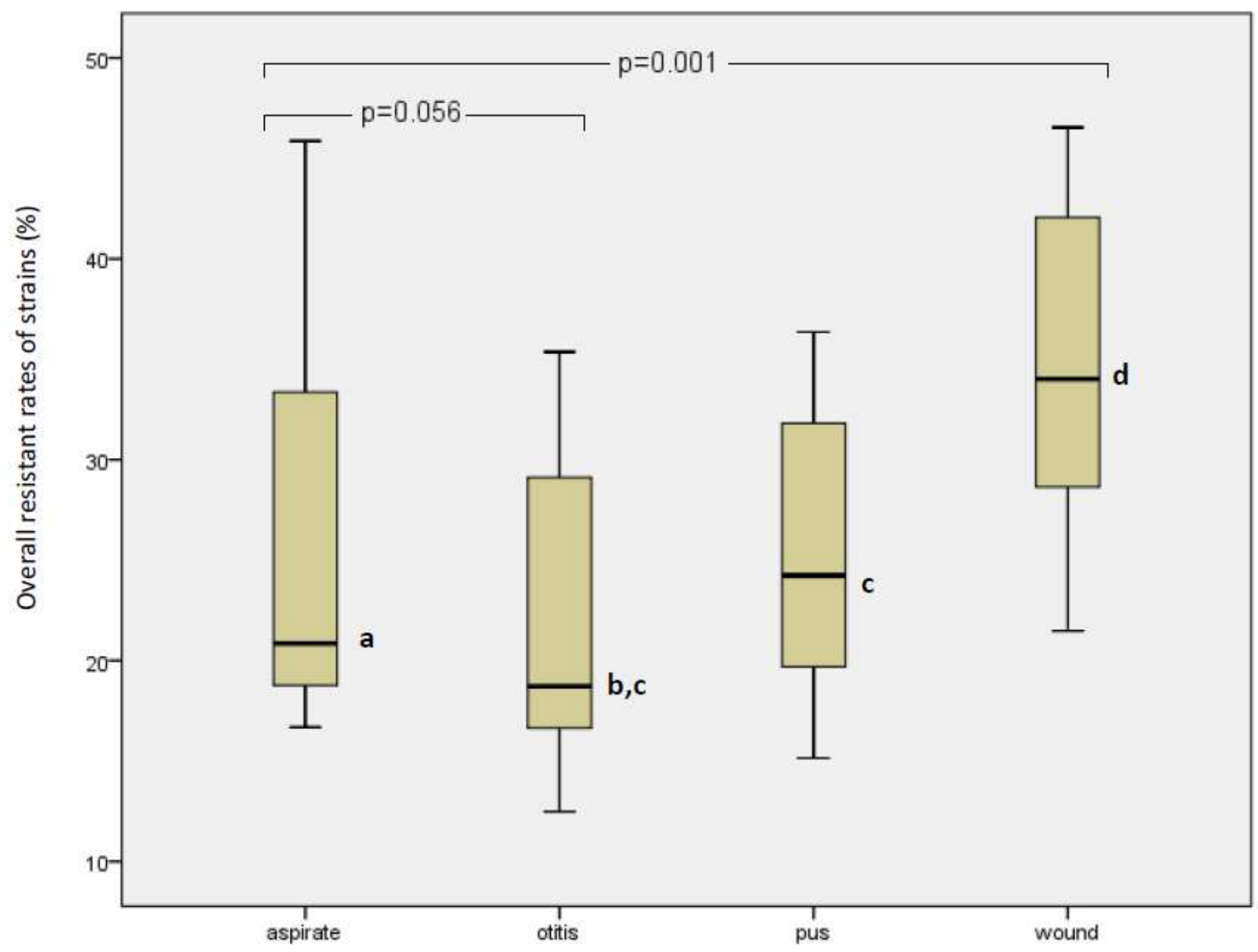

Figure 1

Box plot showing median distribution of antibiotic resistance pattern of Staphylococci strains in collected samples of aspirate $(n=13)$, otitis $(n=16)$, pus $(n=12)$ and wound $(n=25)$. Bold horizontal lines indicate median; and lower and upper whiskers indicate range of resistance rates $(p<0.05$ is significantly difference). 


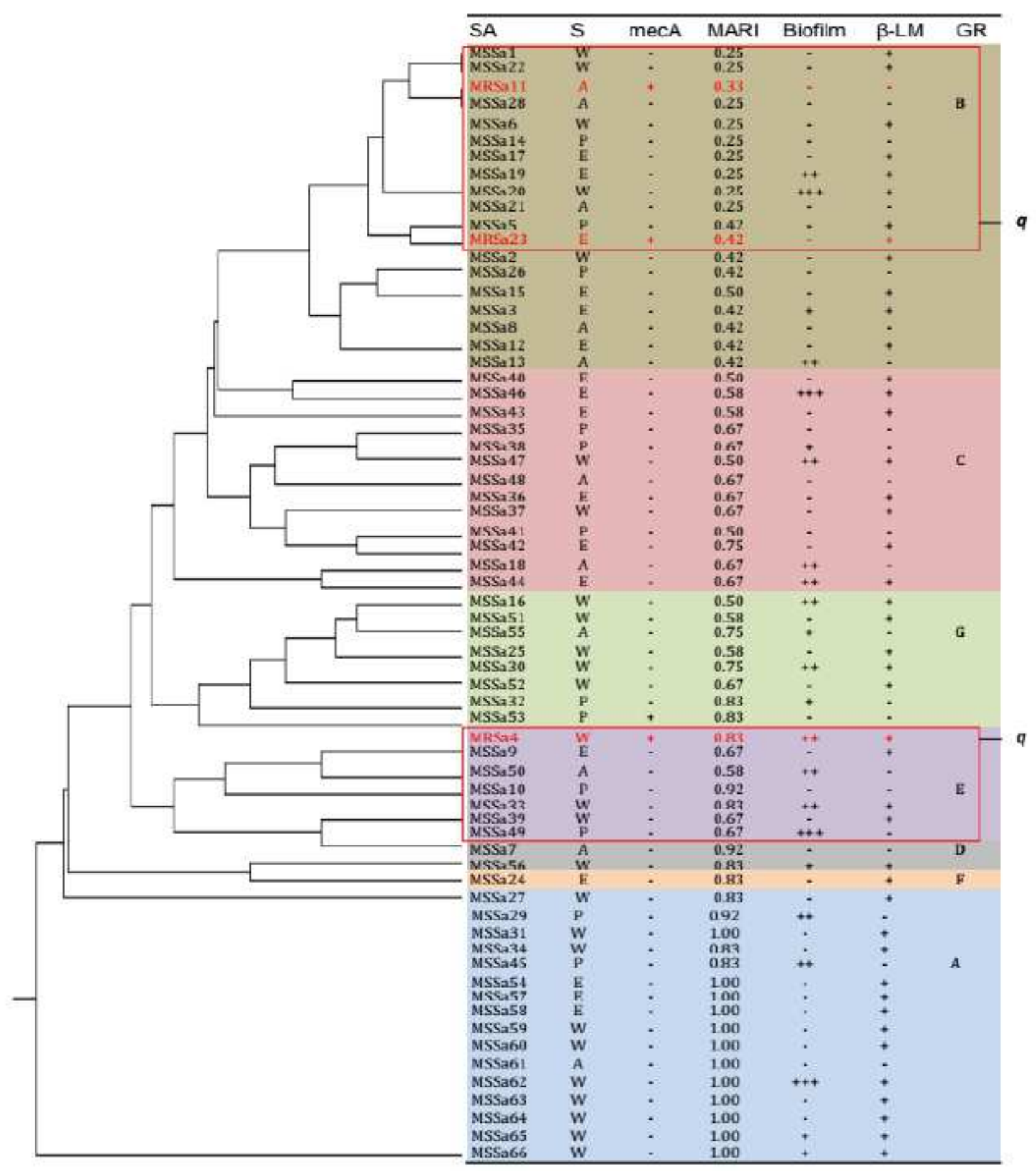

Figure 2

Phylo-antibiotic resistance relatedness with high multi-antibiotic resistance index (MARI), biofilm and beta-lactamase production and mecA genotype (note: + indicate positive and -; negative reaction, biofilm production:+, weak; ++, mild; +++,strong reaction; SS, Source; $\beta$-LM, beta-lactamase; $W$, Wound; A,Aspirate; P,Pus; E,Ear; GR, Phylo-group), q,Diverse multi-resistant strain clustering into same phylo-group. 


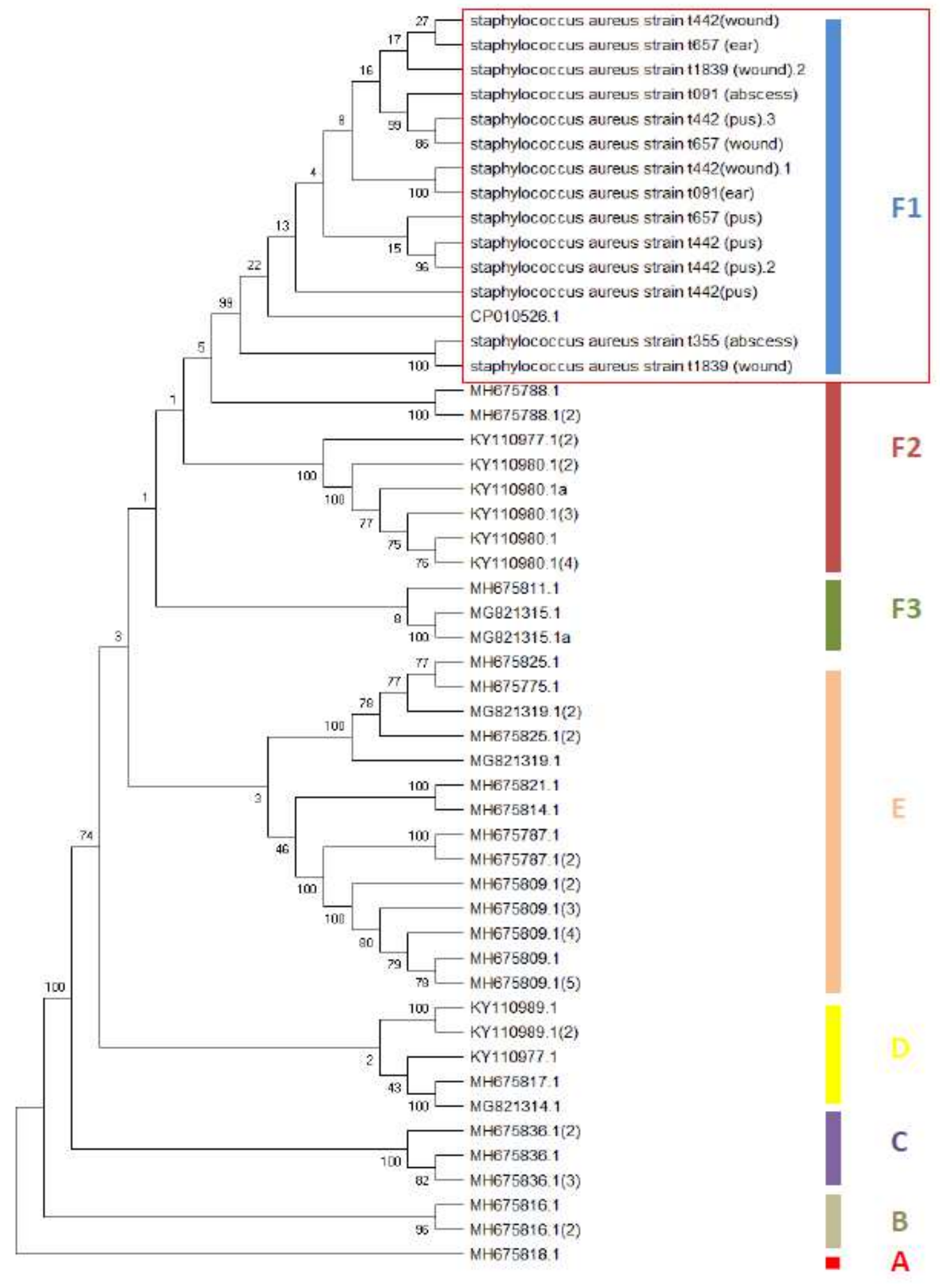

\section{Figure 3}

Neighbor-joining tree showing the phylo-diversity of Staphylococci characterized by heterogeneous spa types ( $t 442, t 657, t 091, t 355)$ and meta-spa sequences of $>95 \%$ identity with their respective accession numbers. Bootstrap values based on 1,000 replications are given at various branching points and sequence divergent was determined with the scale bar. 


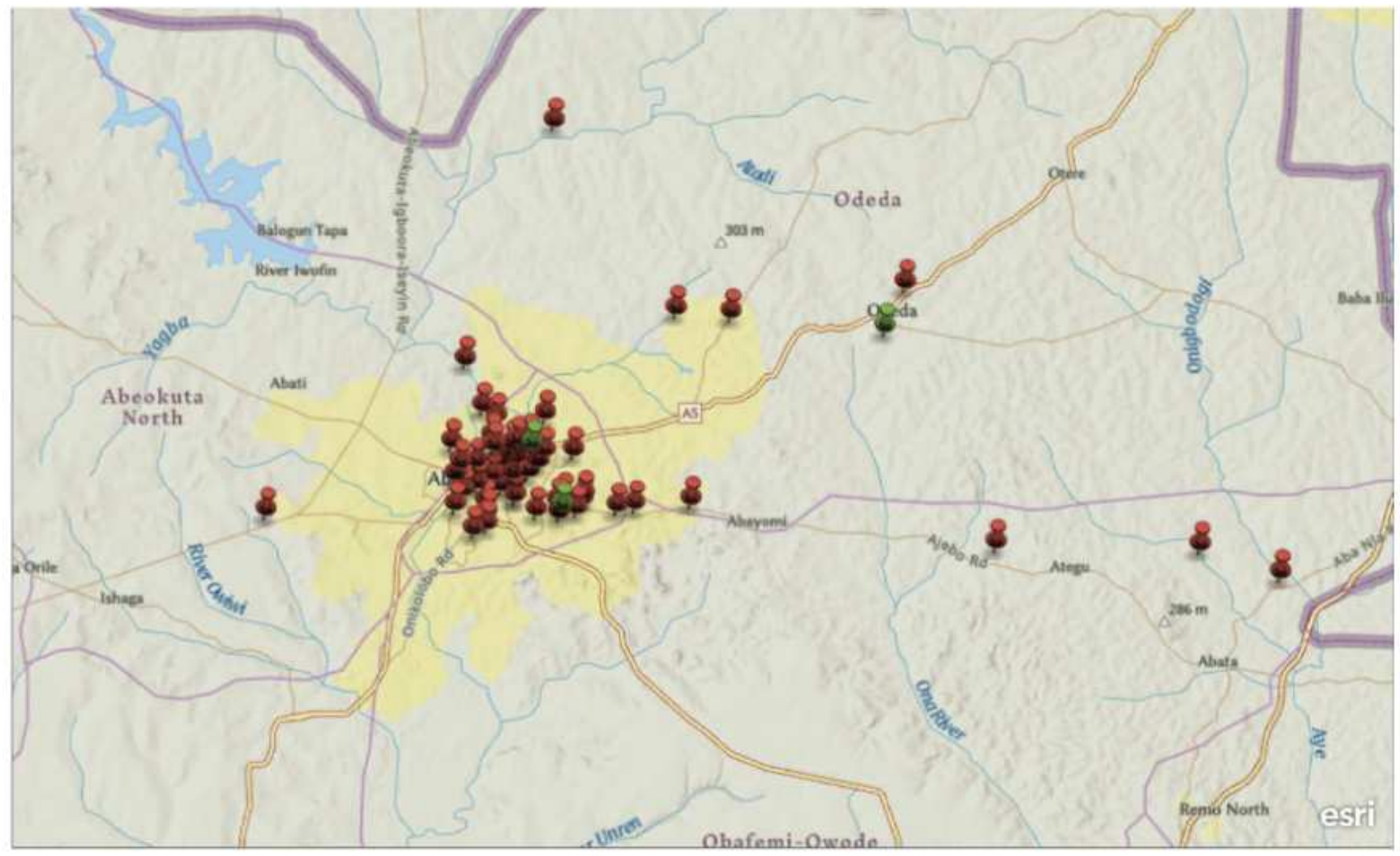

Figure 4

Geospatial mapping and focal dissemination of multi-antibiotic resistance MSSA (green pin) and MRSA (red pin) strains characterised with heterogenous spa genes in distributed in various communities divided according to boundary marks in southwest Nigeria 